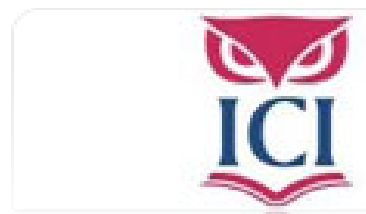

IUS. Revista del Instituto de Ciencias Jurídicas de Puebla A.C.

ISSN: $1870-2147$

revista.ius@hotmail.com

Instituto de Ciencias Jurídicas de Puebla A. C.

México

Cutié Mustelier, Danelia; Méndez López, Josefina

Tribunales y tutela de los derechos humanos en cuba, ¿Una cuestión pendiente?

IUS. Revista del Instituto de Ciencias Jurídicas de Puebla A.C., núm. 21, 2008, pp. 222-242

Instituto de Ciencias Jurídicas de Puebla A. C.

Puebla, México 


\section{TRIBUNALES Y TUTELA DE LOS DERECHOS HUMANOS EN CUBA, ¿UNA CUESTIÓN PENDIENTE?}

Danelia Cutié Mustelier*

Josefina Méndez López ${ }^{* *}$

SUMARIO

1. Planteamiento del tema

2. La tutela judicial de los derechos humanos en Cuba

3. Realidad y exigencia

4. Caracterización de las vías judiciales en la protección de los derechos

5. Principales insuficiencias:

a) Procedimiento de habeas corpus

b) Procedimiento civil

c) Procedimiento contencioso-administrativo

d) La protección penal de los derechos humanos

e) La protección de los derechos humanos en las relaciones laborales

6. Conclusiones

\section{RESUMEN}

En el constitucionalismo contemporáneo ha quedado demostrado que la efectividad de los derechos humanos depende tanto de su reconocimiento constitucional y legal cuanto, y quizás sobre todo, de la existencia de mecanismos susceptibles de garantizar en la práctica su eficacia real. Es por ello que en la generalidad de los textos constitucionales es constatable la regulación de una amplia y novedosa gama de instrumentos jurídicos protectores de los derechos humanos, capaces de prevenir o reaccionar frente a cualquier amenaza o vulneración de los mismos, asignándole a los tribunales un rol protagónico en la tutela de los derechos humanos, al ser considerados la "ga-

\section{ABSTRACT}

In contemporany constitutionalism, it has been demonstrated that effectivity of human rights depends both on its constitutional and its legal recognition, because of the existence of susceptible mechanisms to guarantee real efficiency in every day practice. That is why in most constitutional texts, the regulation of an extended and novel inventory of judicial instruments to protect human rights, are recorded and able to prevent or react against any threat or wounding them, assigning a paramount role to the courts in the protection of human rights, being considered the "day by day guarantee" or

* Profesora de derecho constitucional y vicedecana de la Facultad de Derecho, Universidad de Oriente, Cuba.

** Profesora de derecho constitucional y decana de la Facultad de Derecho, Universidad de Oriente, Cuba. 
rantía del día a día" o garantía por "excelencia". El presente trabajo aborda con una visión crítica, el rol que desempeñan los tribunales cubanos en cuanto a la protección de los derechos humanos, destacando las insuficiencias y limitaciones que inciden en su funcionamiento e impiden que actualmente brinden una tutela eficaz a los citados derechos. the "quarantee of excellence". This work presents with a critical vision, the role accomplished by the Cuban Courts in the protection of human rights, emphasizing restrictions and insufficiencies occurring in its functioning and preventing a better efficiency and tutelage to the human rights.

\section{Planteamiento del tema}

La historia de los derechos humanos y sus garantías corre paralela a la historia de la lucha por la libertad. Desde la antigüedad, cuando aún no se hablaba de derechos humanos en el sentido moderno de la palabra, encontramos referencias a las luchas contra la opresión y el abuso de poder, así como la tendencia a hacerle frente empleando diferentes medios o vías, como la resistencia activa y la pasiva, el juramento de los príncipes de respetar las leyes, el Justicia de Aragón, los orígenes remotos del mandamiento de habeas corpus en la Carta Magna inglesa de 1215, el Preboste de la Corona en Suecia y en Finlandia en el siglo xvi, que sin dudas fueron antecedentes o "chispazos", al decir del profesor Fix-Zamudio, ${ }^{1}$ de los modernos medios de garantías de los derechos, en un mundo agitado y confuso, que transitaba muy lentamente por el camino escabroso y difícil de la defensa jurídica de la libertad.

El constitucionalismo revolucionario del siglo xvIII, específicamente en la Declaración francesa de los Derechos del Hombre y el Ciudadano de 1789 estableció, en el artículo 16, esa primigenia influencia al plantear que no puede existir una sociedad y una ordenación del poder de tipo constitucional sin la garantía de los derechos, previsión que ha tenido un corolario en la generalidad de los textos constitucionales que con mayor o menor rigor sistemático, han regulado las garantías o mecanismos protectores de los derechos y libertades.

Ciertamente el tema de los derechos humanos no puede verse sólo en el sentido estricto de su reconocimiento formal, sino que debe comprender también, los mecanismos de protección que aseguren su real eficacia en las relaciones sociales.

\footnotetext{
${ }^{1} \mathrm{H}$. Fix-Zamudio, La protección jurídica y procesal de los derechos humanos ante las jurisdicciones nacionales, Ed. Civitas, Madrid, 1982, pp. 36ss.
} 
La recepción de los derechos humanos en la Constitución fue un importante momento en la evolución histórica de las garantías de los derechos humanos. En efecto, la consagración constitucional fue y es una condición necesaria para el reconocimiento de los derechos humanos, pero no basta para asegurar su protección real y efectiva.

La propia historia ha demostrado que el sólo reconocimiento constitucional de los derechos fundamentales no es suficiente si no va acompañada de garantías que aseguren la efectividad del libre ejercicio de los derechos.

Ilustrativas son las palabras de Dran al plantear: "Es tan extrema su fragilidad y tan constante su evolución, que las libertades públicas precisan para ejercerse y desenvolverse no sólo un tratamiento especial, sino también y sobre todo, un sistema de protección particularmente eficaz, ya que las libertades no valen en la práctica más que lo que valen sus garantías." ${ }^{2}$

Siendo así, es innegable la necesidad de defensa de los derechos humanos y la justificación de establecer mecanismos eficaces para la tutela de los mismos, capaces de reaccionar frente a cualquier lesión que intente restringirlos, disminuirlos o desconocerlos.

Por eso hoy, en el constitucionalismo más reciente es constatable la amplia y novedosa gama de instrumentos jurídicos que conforman el sistema de garantías de los derechos humanos, que abarca tanto la acción procesal que permite al titular del derecho acudir, solicitando su protección o restablecimiento, a los tribunales, en caso de vulneración del mismo, reconocida como la garantía por excelencia para algunos autores, como Kelsen $^{3}$ y Peces-Barba, ${ }^{4}$ hasta los más disímiles medios de protección que se establecen en dependencia de la tradición jurídica, el desarrollo económico, político y social alcanzado y el grado de perfeccionamiento del sistema legislativo e institucional del país.

Las garantías jurisdiccionales son aquellos mecanismos que constituyen una forma de protección más directa de los derechos humanos. En la generalidad de los países devienen en la garantía del día a día o de primer orden, pues la sola posibilidad de acudir a un órgano imparcial, independiente, dotado de la necesaria fuerza coercitiva para hacer cumplir sus decisiones, integrado por un personal capacitado capaz de aplicar los derechos funda-

${ }^{2}$ M. Dran, citado por J. García Morillo, La protección judicial de los derechos fundamentales, Ed. Tirant lo Blanch, Valencia, 1994, pp. 20.

${ }^{3}$ H. Kelsen, Teoría general del Estado, Ed. Nacional, México, 1980.

${ }^{4}$ G. Peces-Barba, Derechos fundamentales, Facultad de Derecho de la Universidad Complutense, Madrid, 1986, pp. 15. 
mentales de conformidad con su contenido constitucionalmente reconocido, puede permitir a quien ve vulnerado o en trance de serlo un derecho humano, obtener su protección y reparación, lo que sin dudas constituye la gran ventaja de este tipo de garantía con relación a las demás. ${ }^{5}$

La dimensión de esta garantía ha ido evolucionando a lo largo de la historia del derecho en correspondencia con las exigencias y peculiaridades de cada país, quedando hoy conformada por una jurisdicción ordinaria y otra especial o constitucional.

Las garantías jurisdiccionales generales u ordinarias, que Fix-Zamudio denominó remedios procesales indirectos, refiriéndose a los procedimientos ordinarios (civil, penal, laboral y la justicia administrativa) a través de las cuales se protegen los derechos de carácter ordinario, pero que en forma refleja pueden utilizarse para la tutela de los derechos humanos. Esta vía tiene gran trascendencia, sobre todo cuando no existen instrumentos específicos de tutela de los derechos humanos; incluso en muchos países donde existen instrumentos específicos y directos de protección, se exige el agotamiento de la vía judicial ordinaria para poder acudir a éstos. Es decir, que el primer mecanismo de protección de los derechos humanos, es la protección judicial ordinaria. Son los órganos judiciales los que reúnen las condiciones precisas para ejercer esa alta responsabilidad, es a ellos a quienes está constitucionalmente atribuida la función jurisdiccional, esto es, la de decir el derecho que corresponda a cada uno, la misión de juzgar y hacer ejecutar lo juzgado, son ellas quienes han de tutelar los derechos e intereses legítimos entre los cuales se encuentran los derechos humanos y son en definitiva sus sentencias y resoluciones de obligatorio cumplimiento. Por todo ello los órganos judiciales se convierten en la base, en el escalón principal del sistema de garantías de los derechos humanos.

Mientras que las garantías jurisdiccionales específicas son remedios procesales creados exclusivamente para el muy específico fin de proteger los derechos humanos, son por tanto procesos de cognición limitada. Se distinguen por brindar de forma directa, rápida y eficaz tutela a los dere-

\footnotetext{
${ }^{5}$ Múltiples han sido las clasificaciones de los instrumentos garantistas de los derechos humanos; preferimos acogernos a la clasificación siguiente que en el orden metodológico permite una visión integral de los diferentes mecanismos de protección de los derechos: Garantías Jurisdiccionales, Garantías no Jurisdiccionales, Garantías Normativas o Abstractas. Para un análisis más detallado de cada una, véanse: H. Fix-Zamudio, Op. cit., pp. 31-50; J. García Morillo, Op. cit., pp. 26-45, D. Cutié Mustelier, El sistema de garantías de los derechos humanos en Cuba, Tesis en opción al grado de doctora en ciencias jurídicas, Santiago de Cuba, 1999, pp. 33-42; M. Carrillo, La tutela de los derechos fundamentales por los tribunales ordinarios, Centro de Estudios Constitucionales, Madrid, 1995, pp. 24-29.
} 
chos humanos reconocidos por el ordenamiento constitucional, es decir, el modo de proceder debe caracterizarse por la inmediatez, por la máxima urgencia y abreviación en la tramitación y solución, compatibles con un conocimiento adecuado del problema a dilucidar, siendo los efectos del fallo protector esencialmente reparador, es decir, no sólo requiere de la sanción sino que dispone la restitución al afectado en el goce de sus derechos.

$\mathrm{Al}$ decir de Cappelletti, las garantías jurisdiccionales específicas forman parte de la llamada jurisdicción constitucional de la libertad, ${ }^{6}$ la necesidad de su establecimiento se ampara en la fundamentación doctrinal acerca de los inconvenientes que la vía jurisdiccional general u ordinaria ofrece, pues si bien es cierto que constituye la garantía de "primer orden" o las "garantías del día a día" de los derechos humanos, no es menos cierto también que los procedimientos que en esa vía se ventilan suelen ser dilatados y complejos, lo que resulta perjudicial a la protección de los derechos humanos, que en todo caso debe caracterizarse por la rapidez, brevedad y eficacia, dada la naturaleza del bien jurídico tutelado, por tanto, el retraso en la protección del derecho puede convertirla en inútil, pues con frecuencia desaparece la situación que demandaba tal protección, o se llega a tal estado de cosas que la preservación del derecho o el restablecimiento del mismo resulta del todo imposible, de ahí que el elemento temporal integra el logro de la garantía.

Estas garantías jurisdiccionales específicas pueden ser:

Ordinarias, cuando se trata de un procedimiento específico para la defensa de los derechos humanos ante los propios órganos judiciales ordinarios. Ejemplos: el habeas corpus, la Acción de Tutela en Colombia, el procedimiento preferente y sumario en España. Extraordinarias, cuando se trata de un procedimiento específico para la defensa de los derechos humanos ante órganos jurisdiccionales especiales o especializados, como es el caso de los recursos o procedimientos establecidos en algunos países ante los tribunales constitucionales.

\section{La tutela de los derechos humanos en Cuba, Realidad Y EXIGENCIA JUDICIAL}

El 24 de febrero de 1976 fue proclamada públicamente la Constitución Socialista de Cuba, que días antes había sido aprobada mediante un demo-

$\overline{{ }^{6}}$ M. Cappelletti, La jurisdicción constitucional de la libertad, México, 1961, pp. 17ss. 
crático referéndum popular. En materia de derechos humanos, la Constitución de 1976 siguió el modelo constitucional socialista de tipo estatalista, ${ }^{7}$ derivado de la experiencia del constitucionalismo soviético, tanto en la declaración o reconocimiento del conjunto, como en lo referido a la condicionalidad material y al sistema de garantías, sin olvidar los documentos internacionales sobre la materia, pero más que todo consagrando el ideario progresista e independentista de cien años de lucha cuyo máximo referente se encuentra en el pensamiento de José Martí y su exaltación a la dignidad plena del hombre. ${ }^{8}$

La Constitución de 1976 reconoció un amplio conjunto de derechos y libertades a los ciudadanos e individuos, no restringiéndolos a los derechos de la primera generación, sino ampliándolos con la incorporación de los de la segunda generación y en cierta medida sienta las bases para la futura enumeración de los derechos de la tercera generación. ${ }^{9}$

Se agruparon un conjunto de derechos y libertades en el capítulo viI, bajo la denominación "Derechos, Deberes y Garantías Fundamentales". Teóricamente es discutible ese agrupamiento y esa denominación, pues puede interpretarse que los derechos no comprendidos en este capítulo no poseen el mismo rango que aquéllos.

Tal postura constituyente debe ser esclarecida porque no parece admisible que intencionalmente se haya establecido una clasificación jerárquica de derechos, reconociendo a unos mayor valor sociojurídico que a otros, más, si los no incluidos son derechos tan importantes para el hombre, como los derechos al sufragio, a participar en la vida política del país, a la igualdad, a la propiedad y a la herencia, a la libre creación artística, científica e intelectual. ${ }^{10}$

La explicación a esta postura puede encontrarse en la estructura dada al texto constitucional en capítulos y artículos, destacando el Constituyente la importancia y significación de determinados derechos, como por

\footnotetext{
${ }^{7}$ Para un análisis del modelo constitucional socialista en cuanto a las declaraciones de derecho y sus garantías, véase H. Fix-Zamudio, La protección..., Op. cit., pp. 2-46.

${ }^{8}$ J. Fernández Bulté, "Enfoque constitucional cubano de los derechos humanos y su protección”, Seminario sobre Derechos Humanos, Op. cit., pp. 129-134.

${ }_{9}$ El artículo 27 de la Constitución de la República, no reconoce el derecho de medio ambiente, sólo establece la postura del Estado cubano en cuanto a la protección del medio ambiente y el deber de los ciudadanos de contribuir a la preservación del mismo. Para un análisis al respecto puede consultarse, $\mathrm{J}$. Méndez López, D. Cutié Mustelier y A. Loperena, "El derecho a la protección del medio ambiente en el contexto latinoamericano", Revista de la Universidad Eugenio María de Hostos, Ed. Barco de Papel, Puerto Rico, 1997, pp. 81ss.

${ }^{10}$ Véanse fuera de este capítulo, los artículos 134, 40, 55, 28 y 38.
} 
ejemplo: la igualdad, el sufragio, la ciudadanía, al plasmarlos en capítulos aparte, sustrayéndolos con esa intención del núcleo principal de derechos reconocidos bajo el rótulo de fundamentales, siguiendo también aquí el modelo de la Constitución de 1940, que agrupó determinados derechos bajo la denominación de fundamentales, mientras que otros fueron regulados en títulos aparte.

En tal sentido, la lectura del artículo 137 (número correspondiente al texto reformado en 1992) viene a resolver la polémica, pues en él se equiparan todos los derechos contenidos en la Carta Magna, al dotarlos a todos con la garantía de la rigidez constitucional, allí contenida.

Asimismo, no se agotó en la regulación constitucional todo el conjunto de derechos y libertades contenidas en la Declaración Universal de Derechos Humanos de 1948, permitiendo así que disposiciones normativas ordinarias reconocieran determinados derechos, como la personalidad jurídica, la presunción de inocencia, libertad de circulación y emigración, a crear sindicatos y afiliarse a ellos, práctica que implica entender esas normas como una extensión de la Constitución en materia de derechos humanos y que el tema deba ser tratado en dos niveles, a saber: el texto constitucional y la legislación ordinaria. ${ }^{11}$ También se hizo en algunos casos reconocimiento parcial a determinados derechos y otros como el derecho a la vida, al honor, no están indicados de modo expreso.

Empero, en la Constitución se reconocen los derechos al deporte y a la queja, incluso como fundamentales, los que no aparecen reconocidos en la doctrina constitucional, ni en la legislación internacional. Tal regulación debe ser entendida como un aporte de la práctica constitucional y legislativa cubana al tema.

Con relación al sistema de garantías, el texto constitucional cubano no ha sido lo suficiente preciso, aun y cuando denomina al título viII Derechos, Deberes y Garantías Fundamentales, no distingue nítidamente los derechos de las garantías; por el contrario, los preceptos se mezclan no tan felizmente unos con otros, existiendo por un lado, una confusión terminológica entre los derechos y garantías en sentido estricto, consignándose

\footnotetext{
1 Para el análisis de la concordancia del texto constitucional cubano de 1976 en materia de derechos, con los documentos internacionales al respecto, pueden consultarse F. Raimundo Torrado, Los derechos humanos en Cuba, Editora Política, La Habana, 1988; Dávalos Fernández, R., Los derechos humanos en la legislación cubana, Colección de Estudios Jurídicos No. 7, La Habana, 1989, pp. 13-16; A. Mariño, D., Cutié, J. Méndez, La cultura nacional de los derechos humanos. Informe de Investigación, Santiago de Cuba, 1995.
} 
solamente como garantías, las condiciones materiales, ${ }^{12}$ para la realización de los derechos, sin aparecer, por tanto, plasmados en este capítulo los medios o instrumentos adecuados para una pronta y eficaz tutela de los derechos frente a posibles atentados o amenazas de los mismos.

No obstante, dispersos en el texto constitucional se regulan algunas vías o mecanismos que sirven para la protección de los derechos; en primer lugar aparece la garantía de la responsabilidad, consistente en la acción para reclamar y obtener la correspondiente reparación o indemnización ante daño o perjuicio causado indebidamente por funcionario o agente del Estado, con motivo del ejercicio de las funciones propias de sus cargos, ${ }^{13}$ prevista en el artículo 26. Se trata pues, de una fórmula jurisdiccional para restituir derechos e intereses por hechos ilícitos cometidos por agentes del Estado, y se deja a la Ley la regulación de la forma de reclamar y obtener la correspondiente reparación o indemnización.

En segundo lugar aparece la actuación de la fiscalía como el órgano encargado del control y preservación de la legalidad (artículo 127), y la rigidez constitucional prevista en el artículo 137 como garantía abstracta o normativa. Sin embargo, es notoria la ausencia de regulación expresa de las garantías jurisdiccionales. Ante tal situación surgen las preguntas siguientes: ¿No existen las garantías judiciales en el país? ¿Qué papel desempeñan nuestros Tribunales Populares en la protección de los derechos humanos?

Las respuestas a estas interrogantes podemos encontrarlas en el análisis que haremos más adelante, no sin antes señalar que la regulación constitucional de las garantías judiciales de los derechos humanos es insuficiente.

\section{Caracterización de las vías Judiciales en la protección DE LOS DERECHOS (PRINCIPALES INSUFICIENCIAS)}

Con la entrada en vigor de la Constitución Socialista de 1976, el sistema de garantías de los derechos humanos en Cuba se caracteriza por la limitada

\footnotetext{
12 Para un análisis detallado sobre la condicionalidad material como premisa insoslayable para asegurar la viabilidad social del ejercicio de los derechos, véase A. Mariño Castellanos y otros, La cultura nacional de los derechos humanos en Cuba, p. 5; Peraza Chapeau, J., "Protección constitucional de los derechos humanos y su garantía”, en Revista del IIDH, San José, Costa Rica, 1997, pp. 139-155.

${ }^{13}$ Para más detalle, véanse A. R. Brewer Carías, "Fundamentos de los derechos humanos y la Constitución cubana”, en Revista del IIDH, San José, Costa Rica, 1997, p. 181; F. Álvarez Tabío, Comentarios a la Constitución Socialista, Ed. Pueblo y Educación, La Habana, 1988, pp. 120-123.
} 
utilización de los mecanismos jurisdiccionales y la exclusión del recurso de inconstitucionalidad de parte afectada, pues como es sabido el haber concebido el control constitucional tal y como lo hacía el modelo constitucional socialista, únicamente como un remedio político o haberle reconocido sólo una naturaleza política que es lo mismo, alejado de su consideración como instrumento jurídico, impidió su instrumentación posterior como garantía directa de los derechos humanos. ${ }^{14}$

La utilización de los mecanismos jurisdiccionales en la protección de los derechos en Cuba es limitada, aún y cuando la legislación ordinaria vigente expresamente fija a los tribunales entre sus principales objetivos: amparar la vida, la libertad, la dignidad, el honor, el patrimonio, las relaciones familiares y los demás derechos e intereses legítimos de los ciudadanos (artículo 4c Ley No. 82 de 11 de julio de 1997, Ley de los Tribunales Populares). Sin embargo, a los tribunales les han quedado reservadas únicamente las cuestiones de legalidad, no existiendo la jurisdicción constitucional, al quedar reducido el subsistema de garantías jurisdiccionales a las llamadas garantías generales o medios procesales ordinarios, o sea, los procedimientos ordinarios o comunes (civil, penal, laboral, administrativo) a través de los cuales se protegen los derechos de carácter ordinario y de forma refleja o indirecta pueden utilizarse para la tutela de los derechos humanos.

No significa lo anterior, que los procedimientos que se ventilan ante la jurisdicción ordinaria no sean importantes instrumentos para la tutela de los derechos; todo lo contrario, es el proceso judicial la vía ordinaria para la defensa de los derechos; deben ser los órganos judiciales los que en primer lugar apliquen la Constitución; lo que sucede es que, al no existir para la tutela de los derechos cauces procesales específicos (con la sola excepción del habeas corpus), caracterizados por la persecución de la mayor rapidez en la consecución de la protección, la defensa de los derechos humanos se verá, a efectos procesales, equiparada a la de cualquier otro derecho o interés y experimentará las insuficiencias y dilaciones propias del sistema procesal ordinario y del funcionamiento de los órganos jurisdiccionales.

Hay autores que encuentran la justificación del actual diseño del subsistema de garantías jurisdiccionales de los derechos humanos, en el principio de unidad de poder que rige la actuación de los órganos del Estado

${ }^{14}$ Para más detalle sobre el control constitucional en Cuba luego de la entrada en vigor de la Constitución Socialista de 1976, véase A. Mariño Castellanos, "El control de la constitucionalidad de las leyes en Cuba”, Cap. 11, Tesis doctoral, Santiago de Cuba, 1996. 
en Cuba, partiendo del supuesto de la supremacía del órgano legislativo y la subordinación jerárquica de los tribunales a éste; sostienen que dicho órgano no puede ser juzgado en caso de dictar una ley inconstitucional por los tribunales, pues implicaría invadir sus funciones o colocarse por encima de él, con lo cual caen en una confusión doctrinal al mezclar dos instituciones del derecho constitucional: el control de la constitucionalidad de las leyes y las garantías de los derechos humanos.

Siguiendo al profesor Álvarez Tabío, la misión de los tribunales de proteger los derechos humanos, no implica un veto a otro órgano del Estado (o poder dentro del clásico tríptico de Montesquieu) sino la determinación de la norma aplicable al caso concreto, lo cual significa esencialmente administrar justicia.

En ningún caso los tribunales, al aplicar la Constitución, están imponiendo un veto a determinado órgano del Estado. Los jueces al fallar un caso concreto están en el deber de buscar la norma aplicable y cuando desechan una para escoger otra, no están derogando ni vetando la norma desechada, sino limitándose a declarar cuál es el derecho en el caso concreto sometido a su decisión, ${ }^{15}$ es decir que la interpretación y aplicación de las leyes por los tribunales, debe siempre estar regida por la valoración y el respeto a los derechos humanos reconocidos por el texto constitucional.

Ahora bien, cuando lo que se busca es la inconstitucionalidad de una norma, entonces el procedimiento no se ventila ante los tribunales. Para ello existe el control político o abstracto a cargo de la Asamblea Nacional del Poder Popular (artículo 75c).

Por otra parte, el subsistema de garantías jurisdiccionales se distingue en Cuba por su dispersión normativa; esto es, encontrarse en varias leyes y diferentes procesos que no brindan una tutela integral a todos los derechos. Veamos pues, las diferentes vías que integran este subsistema:

a) El procedimiento de habeas corpus, no aparece regulado de modo expreso en el articulado de la Constitución de 1976, pero sí en la Ley 5 de 1977, Ley de Procedimiento Penal, en su capítulo ix denominado del Procedimiento de habeas corpus (artículos 467-478). Se trata de un procedimiento judicial para tutelar el derecho de libertad personal contra detenciones arbitrarias, sin constituir un medio apropiado para la defensa de otros derechos, por lo que el ámbito de protección de esta garantía es muy específico y limitado.

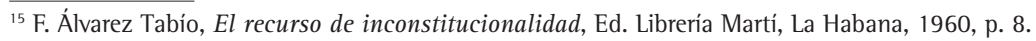


b) El procedimiento civil. Dentro de él se destacan como vías garantistas:

El proceso de amparo en la posesión, constituye una garantía limitada, pues no brinda una defensa integral al derecho de propiedad al referirse tan sólo a la posesión. La actual Ley de Procedimiento Civil, Administrativo y Laboral en su título Iv, artículos 393 al 424 supera la regulación tradicional establecida en el ordenamiento jurídico cubano por la Orden 362 de 1900 del Gobierno de Ocupación Norteamericana, pues el actual amparo en la posesión sobrepasa los estrechos límites de los atentados o despojos en actuaciones judiciales y se extiende a cualquier acto $o$ actuación ocurrida fuera de esto, proveniente de autoridades $u$ órganos administrativos, incluso de particulares. Esto sin dudas constituye una de las ventajas de este proceso unido a la naturaleza sumaria de sus trámites. No obstante, su gran limitación es que no protege el derecho de propiedad en su totalidad al amparar sólo una parte de éste, la posesión.

- Proceso sucesorio. Su ámbito protector es también limitado al brindar tutela sólo al derecho a la herencia previsto en el artículo 24 de la Constitución.

- El proceso reivindicatorio de bienes muebles: Permite la tutela del derecho de propiedad sólo de bienes muebles. Su naturaleza varía según la cuantía del bien en proceso ordinario o sumario, por lo que la tramitación puede ser más lenta o más rápida según el valor del bien reclamado.

- Indemnización por daños y perjuicios: A través de él se puede tutelar cualquier derecho siempre que la lesión resulte un daño o perjuicio para su titular. Es un medio efectivo para la restitución de los derechos (Código Civil, Capítulo rv, Sección segunda, artículos 82-98). Ahora bien, el inconveniente radica en la tramitación que no es uniforme, al no seguirse siempre los mismos términos, esto es en el caso en que la indemnización sea derivada de responsabilidad penal la tramitación será rápida, pues se seguirán los términos fijados para el proceso sumario de alimentos (instrucción 104 de 1982 TSP), mientras que en los demás casos la tramitación varía siguiendo los cauces de un proceso ordinario o sumario según la cuantía de lo reclamado.

Como vemos, la desventaja del procedimiento civil radica principalmente en la falta de uniformidad de los términos y trámites a seguir, lo cual queda en dependencia del tipo de proceso que se inste para reclamar el derecho, por lo que en algunos casos será lenta la tramitación, si se trata de proceso ordinario o más rápida si es sumario. 
c) Procedimiento administrativo: Se conoce con el nombre de contencioso-administrativo, siguiendo la tradición hispánica.

Las ventajas de este procedimiento son: que su ámbito protector abarca cualquier derecho, siempre y cuando el titular tenga la condición de administrado y la lesión provenga de la Administración Pública o sus agentes, así como el efecto anulador de la sentencia estimativa que podrá revocar total o parcialmente la disposición o resolución impugnatoria (artículos 690 y 691 de la Ley de Procedimiento Civil, Administrativo y Laboral).

Mediante este procedimiento pueden impugnarse ante la Sala de lo Civil y Administrativo del Tribunal Supremo Popular y de los restantes Tribunales Provinciales Populares todas las pretensiones que se deduzcan contra las disposiciones de carácter general y las resoluciones dictadas por los organismos de la Administración Central del Estado, sus delegaciones territoriales, así como los comités ejecutivos ${ }^{16}$ de los Órganos Provinciales y Municipales del Poder Popular; incluyendo, además, las cuestiones relacionadas con la Ley de Reforma Urbana ${ }^{17}$ que vulneren derechos legalmente establecidos a favor del reclamante.

Esta vía ha de cumplir determinantes funciones, pues, además de los casos en que autoriza las impugnaciones directas contra actos y violaciones provenientes de la administración y sus agentes, legitima al lesionado para que ante esa jurisdicción reclame indemnización de daños y perjuicios en aquellos casos en que no pueda impugnar directamente el acto o la resolución lesionadora.

No obstante, tiene las limitaciones que prevé el artículo 657 de la Ley de Procedimiento Civil, Administrativo y Laboral en los incisos cuatro y cinco, que excluyen del conocimiento de esta jurisdicción: las materias constitucionales y el ejercicio de la potestad discrecional. Cuestiones éstas que desde luego restringen el ámbito protector de esta vía garantista, sobre todo en el primer caso, pues al plantearse de una manera tan general y amplia el término "materias constitucionales", puede entenderse que las reclamaciones sobre derechos reconocidos en el texto constitucional no podrán instarse ante esta vía, con lo cual se entraría en una contradicción con el artículo 656 inciso primero, que autoriza a la jurisdicción administrativa a conocer todas las pretensiones que se deduzcan contra las disposiciones

\footnotetext{
${ }^{16}$ Los comités ejecutivos de los órganos locales del poder popular desaparecieron como consecuencia de la Ley de Reforma Constitucional de 1992 y en su lugar se crearon las administraciones locales.

${ }^{17}$ En la actualidad los conflictos que se ventilan a través de este procedimiento son los derivados de la aplicación de la Ley General de la Vivienda de 1988.
} 
de carácter general y resoluciones que emanen de la administración y que, en uno y otro caso, vulneren derechos legalmente establecidos a favor del reclamante.

Es cierto que la redacción del inciso cuarto del artículo 657 ofrece dudas y puede pensarse que se excluyen las reclamaciones sobre derechos reconocidos en el texto constitucional, pero pensamos que el sentido del legislador no era excluir tal materia sino las relativas a las cuestiones de constitucionalidad de las leyes y demás disposiciones de carácter general, para lo cual se debe seguir el procedimiento establecido ante la Asamblea Nacional del Poder Popular.

De todas formas, dadas las potencialidades que brinda el procedimiento administrativo para la tutela de los derechos humanos, consideramos debe ser modificada o aclarada la redacción del precepto comentado.

Otra limitante de esta vía es la demora en la tramitación: los términos son generalmente largos, aproximadamente la duración es similar a la de un proceso ordinario, lo cual sin dudas es perjudicial, cuando de la tutela de un derecho humano se trate, que en todo momento debe caracterizarse por la inmediatez.

d) La garantía jurisdiccional penal.

Este nivel de garantía supone el conocimiento que los tribunales de la jurisdicción ordinaria penal según su propia competencia, realicen de los delitos cometidos contra los derechos humanos reconocidos en la Constitución y protegidos por la legislación penal.

Autores, como Martín Rebollo ${ }^{18}$ y Joaquín García Morillo ${ }^{19}$ han expresado sus dudas sobre la idoneidad de esta vía para proteger los derechos fundamentales, argumentando que lo que caracteriza al proceso penal no es la tutela de derechos subjetivos, ni tan siquiera el reponer a la víctima o al ofendido en la situación anterior a la producción de hechos punibles; a través del mismo, se trata más bien de perseguir y sancionar conductas tipificadas como delitos y faltas.

Ciertamente el proceso penal tiene como objeto el enjuiciamiento de las conductas transgresoras de normas penales y eventualmente, la imposición de una sanción en el supuesto de que se determine la efectiva existencia de la transgresión. Pero no es objeto del proceso penal ni la preservación

${ }^{18}$ M. Rebollo, "La vía judicial previa al recurso de amparo constitucional", en Tribunal Constitucional, Vol. 11, Madrid, 1981, pp. 1667-1709.

19 J. García Morillo, El amparo judicial de los derechos fundamentales, Ministerio de Justicia, Madrid, 1985 , p. 102. 
de un concreto derecho subjetivo ni la reparación del daño causado por la violación de aquél.

Es decir, el proceso penal tiene su base en la comisión de un ilícito penal, con independencia de que dicha comisión hubiere lesionado o no derechos ajenos, por lo que la regulación de conductas delictivas se fundamenta no en la lesión de un interés individual, sino en la lesión de bienes considerados como socialmente protegibles y trasciende, por ello, de la mera lesión de un derecho de carácter individual, cuya reparación o reposición puede lograrse a través de otras vías, como por ejemplo la responsabilidad civil.

Sin embargo, es común que la legislación penal de cada país establezca determinadas conductas delictivas, como es el caso de los delitos contra el honor, la vida, etc., cuya comisión implica la violación de ciertos derechos humanos, convirtiéndose de esta forma en un instrumento de protección de los mismos al sancionar hechos que atentan contra el ejercicio de los derechos. Para la puesta en marcha de esta vía protectora de los derechos humanos, se exigen dos requisitos indispensables, que muestran el carácter limitado de la misma:

1) Que la lesión o violación producida haya afectado a un derecho humano.

2) Que esta acción lesiva esté tipificada por la legislación penal como delito.

El Código Penal Cubano, Ley No. 62 de 1987, brinda protección a determinados derechos al prever y sancionar varias figuras delictivas cuya comisión entrañaría la violación de derechos reconocidos por el texto constitucional. De esta forma el título ix, denominado "Delitos Contra los Derechos Individuales", regula una serie de conductas delictivas que atentan contra algunos de los derechos fundamentales recogidos en el capítulo vII de la Constitución, como es el caso de la libertad e inviolabilidad personal, la inviolabilidad del domicilio, inviolabilidad de la correspondencia, libertad de palabra y prensa, los derechos de reunión, asociación, queja y petición, libertad de cultos; también son protegidos el derecho de propiedad y la igualdad, aunque estos dos, como ya dijimos, no aparecen dentro del capítulo VII.

Por otra parte el título x, Delitos contra los Derechos Laborales, tutela penalmente los derechos al trabajo y a la protección e higiene del trabajo, mientras que el capítulo v del título III, protege el derecho a la salud.

Precisamente en la enumeración específica y casuística de conductas delictivas que vulneran determinados derechos radica, como ya expresamos, una de las limitaciones o inconvenientes que presenta esta vía 
garantista, ya que no todos los derechos reconocidos por la Constitución reciben protección penal.

Como se aprecia, de 20 derechos reconocidos en el capítulo vII bajo el rótulo de fundamentales, sólo doce reciben protección penal y de los restantes derechos que se regulan en otras partes del texto constitucional (fuera del capitulo vII) sólo tres: el derecho de propiedad, la igualdad y el derecho al sufragio son ${ }^{20}$ protegidos a través de esta vía.

Resulta significativo que los derechos aquí tutelados, se corresponden en su gran mayoría con los llamados derechos civiles y políticos (aunque no todos los de este tipo reciben dicha protección) y de los derechos económicos, sociales y culturales, sólo los derechos al trabajo, a la protección e higiene del trabajo y a la salud reciben protección penal.

Ante tal situación surge la pregunta: ¿Quiso el legislador establecer un orden de prioridad o jerarquía en la protección penal de los derechos humanos, al tutelar a unos y dejar desprotegidos a otros?

En realidad, el Código Penal ofrece tutela a un grupo amplio pero selecto de derechos, lo cual encuentra justificación en el hecho de que no toda vulneración de un derecho humano implica delito; el legislador sólo ha tipificado como delito aquellas conductas socialmente peligrosas, de gran connotación y repercusión social, lesivas a los derechos humanos, y no cualquier tipo de infracción que puede encontrar su corrección en otras vías garantistas.

Lo que sí llama la atención es que la protección penal esté dirigida en mayor medida a los derechos civiles y políticos y unos pocos derechos económicos, sociales y culturales reciban esta protección.

No pensamos que la fundamentación a esta situación radique en los argumentos esgrimidos por los constitucionalistas europeos con relación a la naturaleza no justiciable de los derechos de la segunda generación y que su realización depende de la política social que trace el legislador, pues en realidad estos derechos han recibido en nuestro país un tratamiento priorizado y el Estado ha puesto todo su empeño en el logro de su real disfrute por el ciudadano, al crear la condicionalidad material necesaria para su viabilidad social.

${ }^{20}$ El Código Penal cubano no recoge la figura delictiva que atenta contra el derecho al sufragio pero la Ley Electoral, Ley 72 de 29 de octubre de 1992 en su título xl, "De lo ilícito de lo electoral", artículo 172 , establece una serie de conductas delictivas, algunas de las cuales atentan contra este derecho, las que serán tramitadas acorde con el procedimiento establecido para los delitos de la competencia de los Tribunales Municipales Populares y serán sancionados con multas de diez a ciento ochenta cuotas. Este fenómeno se le denomina en la doctrina penal como derecho penal accesorio. Véase al respecto $\mathrm{H}$. Heinrich Jescheck, Tratado de derecho penal, Parte general, Vol. 1, Barcelona, 1981. 
Además de que esta vía garantista no abarca a todos los derechos consagrados en la Constitución, otro inconveniente que incide en la efectividad de la misma es que algunos de los derechos por ella protegidos sólo reciben una tutela parcial al no comprender al derecho en toda su dimensión constitucional, tal es el caso del derecho de propiedad, el derecho al trabajo, el derecho de queja y petición y el derecho al sufragio (véanse los artículos 297 del Código Penal con relación a los artículos 45 y 46 de la Constitución, el 292.1c del Código Penal con relación al 63, el 293 del Código Penal con relación al 21 de la Constitución, el 172 incisos b, c, h, plecas 2 y 4 de la Ley 72 de 29 de octubre de 1992, Ley Electoral).

En este aspecto, la generalidad de los tipos delictivos describen conductas que atentan contra el derecho porque obstaculizan el ejercicio del mismo, es decir, impiden que el titular del derecho lo ejerza de acuerdo a su dimensión constitucional; sin embargo, sólo en el caso del derecho al sufragio se configuran dos conductas referidas a posibles excesos o extralimitaciones ${ }^{21}$ que pueden cometer las personas en el ejercicio de sus propios derechos (véanse los incisos b y c del artículo 172 de la Ley Electoral).

Sobre esta cuestión, no queda del todo claro para la propia doctrina constitucional si el restablecimiento de este tipo de garantía sólo se refiere a presuntas violaciones de derechos fundamentales sancionadas penalmente, o a los posibles excesos que se hayan producido en el ejercicio de estos derechos.

Es significativo el hecho de que el Código Penal por una parte restringe su ámbito de protección, al tutelar sólo algunos derechos reconocidos en la Constitución y por otra extiende dicha protección a otros derechos que no están previstos en el texto constitucional, tal es el caso del derecho a la vida (título vIII capítulos II, III, IV, V, VI, VII, VIII) y el derecho al honor (título XII, artículos 318-321 del Código Penal), apreciándose una incongruencia entre la Constitución y el Código Penal, que en este sentido, indudablemente ha sido más avanzado que la Constitución al reconocer y tutelar dos derechos humanos de gran significación recogidos en los documentos internacionales ${ }^{22}$ y que la Constitución debió reconocer.

\footnotetext{
${ }^{21}$ No obstante el Código Penal regula otras figuras delictivas donde se sancionan excesos o extralimitaciones en el ejercicio de algunos derechos, como es el caso del delito de abuso de la libertad de cultos, previsto en el artículo 206, el delito de asociaciones, reuniones y manifestaciones ilícitas (artículos 208 y 209) y la clandestinidad de impresos (artículo 210).

${ }^{22}$ La Declaración Universal de los Derechos Humanos de 10 de diciembre de 1948, reconoce en su artículo 3 el derecho a la vida y en el artículo 12 el derecho al honor. Por su parte el Pacto Internacional de Derechos Civiles y Políticos adoptado el 16 de diciembre de 1966 en el artículo 6 reconoce el derecho a
} 
Lo anterior corrobora nuestro planteamiento inicial de que en Cuba existen dos niveles de reconocimiento de los derechos, a saber: la Constitución y la legislación ordinaria.

En resumen, los inconvenientes que se pueden atribuir a esta vía garantista son:

No puede alegarse ante esta vía cualquier violación de un derecho humano, sino sólo aquellas que están tipificadas como delitos en la legislación penal.

Todos los derechos reconocidos en la Constitución y en el ordenamiento jurídico nacional no reciben tutela penal.

La finalidad principal de la garantía jurisdiccional penal es sancionar las conductas violatorias de los derechos humanos, por lo que la sentencia tiene en estos casos efecto reparador relativo, al no restituir al titular en el goce de su derecho, situación que se agrava más en el caso nuestro, cuando la tramitación de estos asuntos sigue los cauces procesales ordinarios establecidos, por lo que si el proceso contra el autor del delito se prolonga en tales casos, cuando se obtiene la condena, está socialmente olvidada la ofensa.

e) La protección jurisdiccional de los derechos humanos en el ámbito de las relaciones laborales. Este supuesto se refiere a la protección de los derechos humanos cuando la lesión se produce en el marco de las relaciones jurídicas de carácter laboral, siendo el procedimiento laboral la vía adecuada para alegar tales violaciones y encontrar la debida tutela a esos derechos.

El ámbito protector de esta vía abarca fundamentalmente los derechos de indole laboral, siempre que la lesión del derecho que justifique la protección procesal del recurrente, proceda de una entidad laboral.

Ésta es una vía importante para la protección de los derechos de este tipo, ya que sitúa al juez laboral en una posición equivalente a la de cualquier otro de área jurídica distinta. Es decir, el juez o Tribunal Laboral, debe delimitar con su decisión qué es lo que él considera violación del derecho laboral y qué es lo que queda al margen de aquélla.

Además de esta importante actividad interpretativa que deberá realizar el juez en la defensa de estos derechos, la vía laboral ofrece ventajas para la eficaz tutela de los mismos, que se resumen en:

1) Los efectos de la sentencia, que dispondrá en los casos en que se declara la existencia de la vulneración alegada:

la vida y el artículo 17 el derecho al honor. 
- La reposición de la situación del trabajador al momento anterior a producirse la lesión.

- La reparación de las consecuencias derivadas del acto, incluida la indemnización que procediera.

2) El procedimiento basado en los principios de sencillez, celeridad y oralidad. No obstante las referidas ventajas, el diseño actual de la jurisdicción laboral en Cuba ofrece limitaciones que impiden que sea una vía óptima en la tutela de los derechos humanos.

La primera de estas limitantes es:

- La existencia de diversos regímenes especiales en materia de disciplina laboral y del trabajo en cuyos casos, los conflictos con la administración no se ventilan ante los tribunales. A pesar de que el Decreto-Ley No. 176 de 15 de agosto de 1997, crea un sistema de justicia laboral que abarca la casi totalidad de las actividades laborales y reduce la gran diversidad de procedimientos especiales vigentes en el país para la solución de los conflictos disciplinarios, aún es apreciable la existencia de estos regímenes en algunas esferas como: el Sistema de Órganos Aduaneros, los contingentes de construcción y agrícola (en materia de disciplina laboral), las Unidades Básicas de Producción Cooperativa y las direcciones municipales, provinciales y nacionales de las organizaciones sociales y de masas, así como el personal civil de las Fuerzas Armadas y el Ministerio del Interior (en materia de disciplina y derechos laborales).

En estos casos los conflictos continuarán siendo resueltos a través de los procedimientos especiales creados para cada uno, quedando por tanto excluidos de la garantía judicial.

Llama la atención el hecho de que aún y cuando este cuerpo legal, reduce considerablemente los regímenes especiales, sin embargo el artículo 15 del propio Decreto-Ley, en contradicción con el propósito que lo anima, autoriza la existencia de un procedimiento especial para la solución de los conflictos derivados de la imposición de la medida de separación del sistema en sectores, donde fueron eliminados tales procedimientos especiales.

- Otra limitante de esta garantía es la simplificación del uso de la vía judicial surgida con la creación de los Órganos de Justicia Laboral de Base por el Decreto-Ley 132 de 9 de abril de 1992, órgano de jurisdicción delegada competente para dirimir los conflictos surgidos entre los trabajadores y entre éstos y la entidad empleadora: es la instancia definitiva con respecto a los conflictos surgidos por la aplicación de medidas que no modifican 
o lo hacen por un tiempo determinado el estatus del trabajador, por lo que reduce la actuación de los tribunales sólo para aquellas reclamaciones que se establezcan contra las decisiones de los órganos de justicia que impliquen una variación definitiva de la situación laboral del trabajador y en materia de derechos laborales.

Es significativo, además, que contra lo resuelto por los Tribunales $\mathrm{Mu}-$ nicipales Populares no procede recurso alguno.

Por otra parte la eficacia en la tutela de los derechos laborales puede ponerse en peligro si tenemos en cuenta el hecho de que la vía protectora es el propio procedimiento ordinario laboral, donde se ventilan las reclamaciones por presuntas lesiones de derechos humanos de los trabajadores, unidos a cuestiones de mera legalidad, lo que conduce a que la protección de los derechos humanos solicitada ante esta vía se haga de una manera indirecta o de forma equivalente a la de cualquier otro derecho o interés alegado.

\section{Conclusiones}

En resumen, a las garantías judiciales en Cuba les son inherentes las siguientes características:

- Ventajas o potencialidades:

- La función de impartir justicia dimana del pueblo y es ejercida a nombre de éste por los tribunales (artículo 120 de la Constitución).

- Los tribunales son órganos independientes e imparciales (artículos 121 y 122 de la Constitución).

- La fuerza obligatoria de sus fallos (artículo 123 de la Constitución).

- Efectos reparadores de los fallos.

- Composición dual, integrados por jueces legos y profesionales (artículo 124 de la Constitución).

- Elección popular de los jueces.

- Condiciones políticas, morales y sociales para ostentar la condición de juez.

Ventajas que indican que nuestros tribunales reúnen condiciones para constituirse en garantes máximos de los derechos humanos.

- Limitaciones o inconvenientes:

- No existe regulación expresa de las garantías jurisdiccionales en el texto constitucional. 
- Se trata de un sistema disperso en sede judicial ordinaria, integrado por los diferentes procesos ordinarios o comunes (civil, administrativo, penal, laboral) que poseen naturaleza distinta y que se ventilan en diferentes instancias.

- No existe uniformidad en la tramitación, los términos varían según la naturaleza de los procesos utilizados.

- En sentido general estos procedimientos brindan tutela a determinados derechos en específico y no a una pluralidad de ellos (excepto el administrativo).

- Al estar diseñados estos procedimientos para ventilar cuestiones de legalidad, la defensa de los derechos humanos se puede realizar sólo de manera indirecta o equiparada a la de cualquier derecho o interés legítimo, lo cual disminuye prima facies la eficacia de dicha protección, que dada la naturaleza del bien jurídico tutelado (derechos humanos) debe gozar de un carácter preferente, pues de lo contrario dicha tutela sería tardía, cuando no ineficaz.

- A la tutela de los derechos humanos ante los tribunales le son atribuidas las dilaciones e inconvenientes derivados del sistema procesal ordinario y del funcionamiento de los órganos jurisdiccionales (tales como lo formal, lento, costoso y complejo principalmente de la tramitación de los procesos que se ventilan ante esta vía).

Lo anterior conduce a plantear que el subsistema de garantía jurisdiccional en Cuba requiere de un perfeccionamiento, para que pueda cumplir con calidad y eficacia la importante función de defensa de los derechos humanos, máxime cuando los tribunales ordinarios están entre los protagonistas de esta alta misión que le ha sido encomendada por la citada Ley 82/97, Ley de los Tribunales. Dicho perfeccionamiento puede estar encaminado al diseño en sede judicial ordinaria de un mecanismo específico, directo, ágil, breve, preferente y sumario para la tutela de los derechos humanos.

\section{REFERENCIAS}

Aguiar de Luque, Luis, "Las garantías constitucionales de los derechos fundamentales”, Revista de Derecho Político de la UNED, No. 19, Madrid, 1991.

Alexy, Robert, Teoría de los derechos fundamentales, cEc, Madrid, 1993.

Álvarez Tabío, Fernando, Origen y evolución de los derechos del hombre, La Habana, 1942. 
, El proceso contencioso administrativo, Editorial Librería Martí, La Habana, 1958.

, El recurso de inconstitucionalidad, Editorial Librería Martí, La Habana, 1960.

Comentarios a la Constitución Socialista de 1976, Editorial Pueblo y Educación, La Habana, 1988.

Arenas Salazar, Jorge, La tutela, una acción humanitaria, Ediciones Doctrina y Ley, Colombia, 1993.

Atienza, Manuel, Peces-Barba, Gregorio y Díaz, Elías, Politica y derechos humanos, Fernando Torres Editor, Valencia, 1976.

Atienza, Manuel, Marx y los derechos humanos, Editorial Mezquita, Madrid, 1983.

Asensi Sabater, José, Constitucionalismo y derecho constitucional, Editorial Tirant lo Blanch, Valencia, 1996.

Bobbio, Norberto, El tiempo de los derechos, Sistema, Madrid, 1993.

Böckerforde, Ernest, Escrito sobre derechos fundamentales, Baden-Baden, Alemania, 1993.

Brewer-Carías, Allan, "Fundamentos de los derechos humanos y la Constitución cubana”, Seminario sobre Derechos Humanos en Revista del IIDH, Costa Rica, 1997.

Cappelletti, Mauro, La jurisdicción constitucional de la libertad, Giufrè, Milan, 1976.

Carrillo, Marc, La tutela de los derechos fundamentales por los tribunales ordinarios, cEc, Madrid, 1995.

Cassese, Antonio, Los derechos humanos en el mundo contemporáneo, Editorial Ariel, Barcelona, 1991.

Cruz Villalón, Pedro, Derechos fundamentales y legislación. Estudios de derecho público en homenaje a Ignacio de Otto, Servicio de Publicaciones, Universidad de Oviedo, España, 1993.

Fioravanti, Mauricio, Los derechos fundamentales. Apuntes de historia de las constituciones, Trotta, Madrid, 1997.

Fix-Zamudio, Héctor, La protección jurídica y procesal de los derechos humanos ante las jurisdicciones nacionales, Editorial Civitas, Madrid, 1982.

García Morillo, Joaquín, La protección judicial de los derechos fundamentales, Tirant lo Blanch, Valencia, 1994. 